\title{
Hybrid Geoid Model: Theory and Application in Brazil
}

\author{
DANIEL ARANA ${ }^{1}$, PAULO O. CAMARGO ${ }^{1,2}$ and GABRIEL N. GUIMARÃES ${ }^{3}$ \\ ${ }^{1}$ Programa de Pós-Graduação em Ciências Cartográficas, Faculdade de Ciência e Tecnologia, \\ Universidade do Estado de São Paulo/UNESP, Rua Roberto Simonsen, 305, 19060-900 Presidente Prudente, SP, Brazil \\ ${ }^{2}$ Departamento de Cartografia, Universidade do Estado de São Paulo/UNESP, \\ Rua Roberto Simonsen, 305, 19060-900 Presidente Prudente, SP, Brazil \\ ${ }^{3}$ Instituto de Geografia, Universidade Federal de Uberlândia/UFU, Campus Monte Carmelo, \\ Av. Goiás, 2000, 38500-000 Monte Carmelo, MG, Brazil
}

Manuscript received on November 24, 2016; accepted for publication on March 2, 2017

\begin{abstract}
Determination of the ellipsoidal height by Global Navigation Satellite Systems (GNSS) is becoming better known and used for purposes of leveling with the aid of geoid models. However, the disadvantage of this method is the quality of the geoid models, which degrade heights and limit the application of the method. In order to provide better quality in transforming height using GNSS leveling, this research aims to develop a hybridization methodology of gravimetric geoid models EGM08, MAPGEO2015 and GEOIDSP2014 for the State of São Paulo, providing more consistent models with GNSS technology. Radial Basis Function (RBF) neural networks were used to obtain the corrector surface, based on differences between geoid model undulations and the undulations obtained by GNSS tracking in benchmarks. The experiments showed that the most suitable interpolation for correction modeling is the linear RBF. Checkpoints indicate that the geoid hybrid models feature root mean square deviation $\pm 0.107, \pm 0.104$ and $\pm 0.098 \mathrm{~m}$, respectively. The results shows an improvement of 30 to $40 \%$ in consistencies compared with the gravimetric geoids, providing users with better quality in transformation of geometric to orthometric heights.
\end{abstract}

Key words: EGM08, GEOIDSP2014, GNSS leveling, MAPGEO2015, neural network.

\section{INTRODUCTION}

The altimetric component is fundamental for a variety of scientific and engineering applications, such as topographic and geodesic surveying, coastal studies, engineering projects, dams, irrigation and other things. However, the GNSS (Global Navigation Satellite Systems) reference surface (ellipsoid) has no connection with the Earth's gravity field, thus equal values of geometric height can occur in different levels or uneven

Correspondence to: Daniel Arana

E-mail: arana990@gmail.com 
height values may occur on the same equipotential surface of the gravity field (Freitas and Blitzkow 1999). For this reason, many altimetric applications cannot directly use the height component from GNSS. In the first place the geometric height must be reduced to normal, orthometric or dynamic height, and usually quasi-geoid or geoid models are used to aid this conversion ( Featherstone 2000, Kotsakis and Sideris 2001, Torge 2001, Seeber 2003).

Some users such as oceanographers and geophysicists require decimeter quality for geoid model (Kuroishi 2009), but certain geodetic and cartographic applications require a quality close to $1 \mathrm{~cm}$, such as global unification of vertical datum and deglaciation studies (Plag and Pearlman 2009).

The geometric heights obtained by GNSS/leveling in benchmarks allow users to have the distance between the reference ellipsoid and the geoid surface, i.e., the geoid undulation or geoid height. This value is considered closer to the real static geoid than the gravimetric geoid models, for this reason benchmarks are used for evaluation of gravimetric geoid models. However, we must bear in mind that even the geoid from benchmarks is not the "true" geoid. Since different types of measurements and techniques lead to the benchmark geoid, systematic and aleatory errors are present, such as leveling errors, GNSS positioning errors and permanent tidal systems errors.

Another application of GNSS/leveling in benchmarks is the refinement of the gravimetric geoid which has been done by many countries around the world, here we call hybridization process. The integration of GNSS/leveling and gravimetric geoid models gives rise to hybrid geoid models. The principle method is fitting a corrector surface obtained by interpolation in a chosen gravimetric geoid. The generation of this surface is discussed in depth in subsequent sections. Studies have shown that these models are compatible with geodetic reference frames and have provided better quality results in the transformation of geometric to orthometric heights than gravimetric geoid models.

The improvement potential of hybrid geoid models is to the centimeter level, e.g., the case of Japan, with an root mean square difference (RMSD) of $\pm 0.02 \mathrm{~m}$ (Miyahara et al. 2014); cities of China (Hong Kong and Shenzhen) showed an RMS of $\pm 0.01 \mathrm{~m}$ (Chen and Yang 2001); the United States (CONUS contiguous United States) presented an RMS of $\pm 0.01 \mathrm{~m}$ (Roman et al. 2010); Turkey achieved an RMS of $\pm 0.03 \mathrm{~m}$ (Erol and Erol 2013); and South Africa observed an RMS of $\pm 0.07 \mathrm{~m}$ (Chandler and Merry 2010). Other countries have also used the hybridization, in the case of Canada (NRCan 2014), South Korea (Lee et al. 2012, 2013) and Australia (Fotopoulos et al. 2002, Featherstone et al. 2005).

This paper describes a case study showing the methodology applied to obtain a hybrid geoid model in a region very important economically in Brazil, the State of São Paulo. The corrector surfaces were generated by neural networks RBF and the Kriging method.

\section{GRAVIMETRIC GEOID MODELS}

Among the several geoid models already published, the EGM (Earth Gravitational Model) series deserves mention. The EGM96 was the first model of the series. This model was conducted by the NGA (National Geo-spatial Intelligence Agency) in partnership with the GSFC (Goddard Space Flight Center) in mid of 90s. The latest model in the series, the EGM08, reached degrees 2190 and order 2159 of spherical harmonic function coefficients, with a resolution of 5' and accuracy around $\pm 0.15 \mathrm{~m}$ (Pavlis et al. 2012). A global analysis by Pavlis et al. (2008) of EGM08 undulations compared to the undulations obtained by GNSS tracking in 12,305 benchmarks discloses an RMS $\pm 0.103 \mathrm{~m}$. Discrepant results were obtained by Barthelmes 
and Köhler (2012), using 12,036 points in comparison. Then, the RMS obtained was $\pm 0.239 \mathrm{~m}$. For Brazil, the statistics obtained by Matos et al. (2012) also diverge from ICGEM (2015). The first, using 844 points, obtained an RMS $\pm 0.330 \mathrm{~m}$, while the ICGEM, with 1,112 points, showed an RMS $\pm 0.460 \mathrm{~m}$.

In the case of Brazil, MAPGEO2010 (Mapa Geoidal - 2010) was the official geoid model for the country until 2015, when the newest model came out, MAPGEO2015. This series of national-scale models was developed in partnership between IBGE (Instituto Brasileiro de Geografia e Estatística) and EPUSP (Escola Politécnica da Universidade de São Paulo). The methodology used to create these models was Fast Fourrier Transform (FFT) and the modified Stokes integral, with use of the Removed-Restore technique, where the EIGEN-6C4 (Förste et al. 2014) to degree and order 200 was used to obtain the medium and long wavelengths. The last geoid model has an improvement of $20 \%$ in comparison with its antecessor in consistence with GNSS positioning, providing to users an RMS of $\pm 0.17 \mathrm{~m}$, comparing 592 points tracked by GNSS (IBGE 2015).

Since the area of Brazil is $8,515,767 \mathrm{~km}^{2}$, the common practice which in a lot of States has been to develop its own local geoid model for scientific and technical purposes. The State of São Paulo, as an important economic region, has many different geoid models. Since 2008 the GEOIDSP (Geoide de São Paulo) series have been elaborated, with the same methodology of the MAPGEO series. The last local geoid model developed for the State of São Paulo was the GEOIDSP2014 (Guimarães et al. 2015), which used the EIGEN-6C3STAT (Förste et al. 2013) up to degree and order 200 for obtaining medium and long wavelengths. According to Guimarães et al. (2015), the validation of GEOIDSP2014 through 168 points tracked by GNSS showed an RMS $\pm 0.21 \mathrm{~m}$.

The schedule to determine the reginal geoid model using FFT can be described in 5 steps (Blitzkow et al. 2009):

1. Calculation of point free air gravity anomalies through terrestrial gravimetric data (coordinates, orthometric height and gravity acceleration);

2. Calculation of complete Bouguer anomalies in order to derive mean free air gravity anomalies. The 5 ' x 5' grid of these anomalies was computed from point gravity data. Over the ocean, DTU10 was used;

3. Calculation of Helmert gravity anomalies referred to the surface of the Earth. These are obtained from the mean free air anomaly by adding Direct Topographical Effect (DTE), Direct Atmospheric Effect (DAE) and Secondary Indirect Topographical Effect (SITE) (Ellmann and Vaníček 2007);

4. Modified Stokes' kernel integration with the use of the spectral decomposition to calculate the cogeoid;

5. Primary Indirect Topographical Effect (PITE) was added to co-geoid heights to obtain geoid heights (Martinec and Vaníček 1994, Martinec 1998).

\section{GNSS POSITIONING AND GEOID MODEL INTEGRATION}

The integration of satellite positioning technologies with the various existing geoid models has different purposes, one of which gives rise to GNSS leveling technique and other results in the geoid hybrid models. For the development of these techniques, knowledge of the methods and concepts of GNSS positioning is fundamental to obtain the ellipsoidal height and geoid models to calculate the geoid undulations. 
Regarding the gravimetric geoid models, many computation techniques can be used, such as numerical integration of Stokes formula directly or using Fast Fourier Transform (FFT), Least Square Collocation (LSC), spherical harmonic functions developed in series, direct calculation by the difference between the ellipsoidal height and orthometric height (from spirit leveling) and radar altimetry (in the oceans) (Featherstone and Sideris 1998, Sideris 2013). But a combination or integration between techniques can provide better results in terms of compatibility.

Although there are many techniques and methods to obtain gravimetric geoid models, these are commonly validated by GNSS survey in benchmarks (Seeber 2003). For this reason the integration between these geoid models and GNSS leveling data can make it more consistent with satellite tracking.

Three surfaces are considered in geometric to orthometric transformation height: the physical surface of the Earth, where geodesic operations are carried out; the geoid surface, adopted as altimetric reference; and the ellipsoidal surface, limiting the geometric model adopted for the Earth, where geodesic calculations are performed. This assumption can be seen in Figure 1.

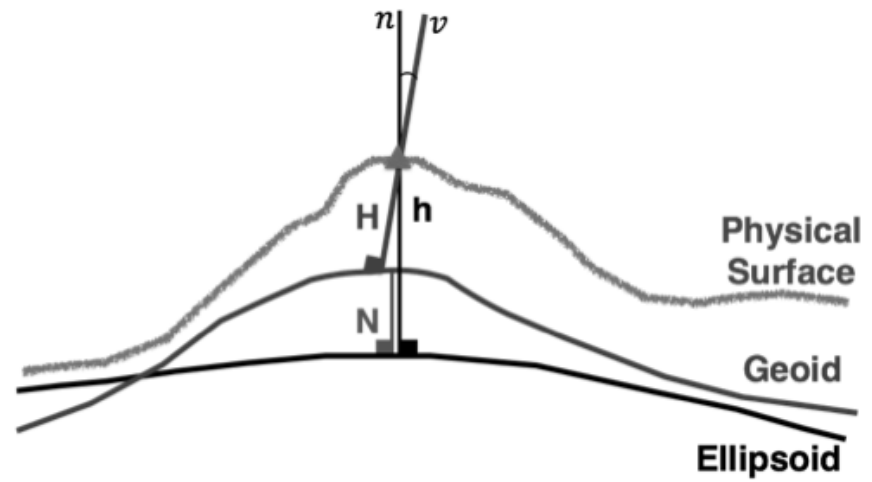

Figure 1 - Physical, geoid and ellipsoid surface (see the colors in the online version).

A simplified mathematical model of the relationship between geometric $(h)$ and orthometric $(H)$ height is considered from the coincidence between the vertical $(v)$ and normal $(n)$ lines.

$$
N(\phi, \lambda)=h(\phi, \lambda)-H(\phi, \lambda)
$$

According to Jekeli (2000) and Sjöberg (2006), the consideration of coincidence between the lines can lead to an error of $0.00001 \%$ to $0.00002 \%$. This approach limits error to no more $1.6 \mathrm{~mm}$ in an extreme case where the elevation reaches $8,000 \mathrm{~m}$.

Following these assumptions, the methodology summarized to obtain hybrid geoid models is shown in Figure 2. The input data for hybrid geoid generation are GNSS/leveling geoid heights $\left(N_{G N S S}\right)$ and a gravimetric geoid grid $\left(N_{\text {model }}\right)$. The hybridization is processed in three steps. First, the calculation of offsets for each GNSS/leveling point; second, the generation of corrector surface; and third, fitting the obtained surface to the gravimetric geoid grid.

Initially the hybrid models depend on offsets obtained between GNSS data from benchmarks $\left(N_{G N S S}\right)$ and a gravimetric geoid model $\left(N_{\text {model }}\right)$. These offsets, calculated according equation 2 , are regarded as corrections $(\Delta N)$ to the gravimetric geoid model.

$$
\Delta N(\phi, \lambda)=N_{G N S S}(\phi, \lambda)-N_{\text {model }}(\phi, \lambda)
$$




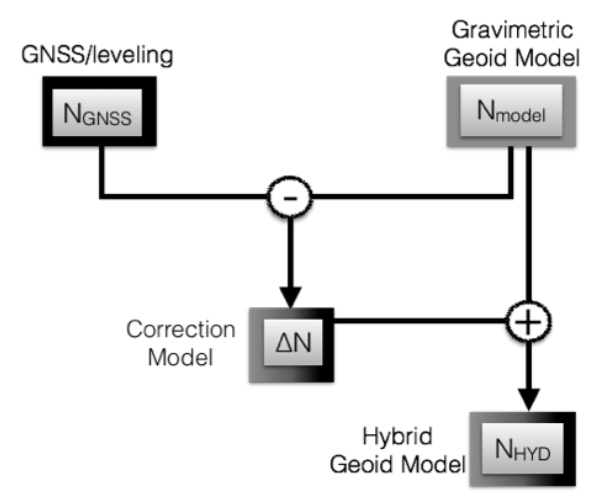

Figure 2 - Methodology of Hybrid Geoid Models (see the colors in the online version).

However, before treating the offset as corrections it is necessary to transform them in an equal grid resolution of gravimetric geoid model, i.e., a corrector surface. Figure 3 illustrates the offsets $\Delta N_{1}$ to $\Delta N_{10}$ (top) and the resultant corrector surface (down) obtained by interpolation. Once a benchmarks network is available, the modeling corrections can be performed by interpolation, estimating correction $\left(\Delta N^{\prime}\right)$ near the points with known offset. According to the expression 2, positive corrections indicate that the geoid model has a positive trend and negative values indicate a negative trend for the region.
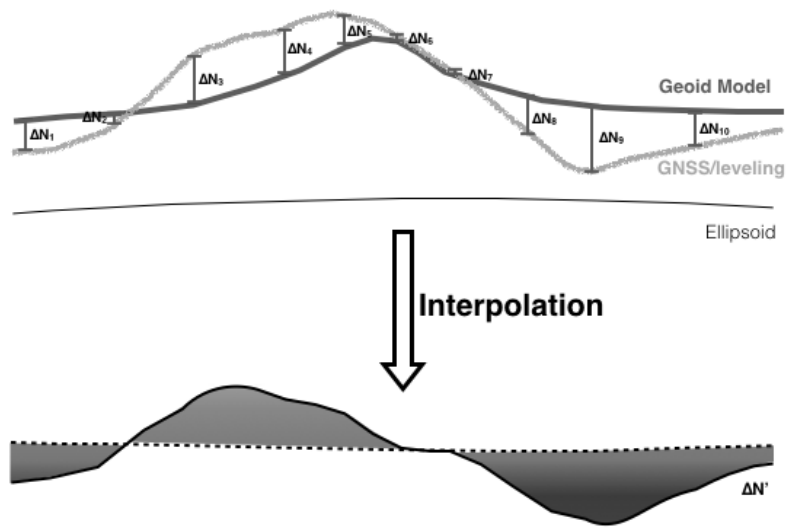

Figure 3 - Corrector surface generation (see the colors in the online version).

Once the offset interpolation is finished, the corrector surface generation is complete and can be added in the gravimetric geoid model grid (equation 3). The hybrid geoid model is obtained from the sum of the grids.

$$
N_{H Y D}(\phi, \lambda)=N_{\text {model }}(\phi, \lambda)+\Delta N^{\prime}(\phi, \lambda)
$$

The refinement of the conventional geoid is performed by the corrector surface $\left(\Delta N^{\prime}\right)$. For this reason, adequate surface representation is crucial for a good quality of the hybrid model. There are several interpolation methods found in the literature for modeling geoid model offsets, such as the multiquadric (Hardy 1975), the weighted average (Chen and Luo 2004), the bilinear and bicubic (Featherstone 2000), the poly- 
nomial surfaces (Fotopoulos et al. 2002); Shepard (Chen and Luo 2004); and Kriging (Chandler and Merry 2010). However, the most widely used method of interpolation is LSC (Fukuda et al. 1997, Featherstone 2000, Fotopoulos et al. 2002, Featherstone et al. 2005, Kuroishi et al. 2002, Chen and Luo 2004, Roman et al. 2004, 2010, Miyahara et al. 2014). An interesting point of this interpolating is that it considers the spatial distribution of observational errors, thus the method requires a covariance matrix of data.

Some authors have been using Artificial Neural Networks (ANN) to obtain geoid undulations (Maia and Segatine 2003, Kavzoglu and Saka 2005, Veronez et al. 2011). With the results, this type of interpolator has been found to have great potential in modeling offsets. Moreover, Fazio and Roisenberg (2013) prove mathematically that these interpolators deliver results equivalent to the Kriging method and can produce identical results if properly configured. In particular, RBF (Radial Basis Function) neural networks are much faster than the Kriging method because the RBF interpolation weights need not be recomputed for each interpolated point.

However, the selection of the interpolation method to represent the corrector surface must be performed empirically as specific interpolation can better represent the spatial reality of the data and the study site (Chen and Luo 2004).

\section{HYBRID GEOID MODELS}

Since nowadays GNSS positioning is widely used for leveling purposes, users must perform height transformation. For this, it is essential to focus on more accurate geoid models. For this research, methods and techniques on the geoid calculation have been improved. The most accurate results for geoid models are centimeter or decimeter-level, according to region extension, methodology, geopotential model, gravimetric data and GNSS/leveling data for validation.

More gravimetric data can make the geoid model more realistic, but in some cases it does not show any improvement in comparison with GNSS/leveling points. This happens not only because of uncertainties of gravimetric and GNSS/ leveling data but also because the two techniques are not completely compatible. The cause of this imperfect compatibly is source of geoid undulation quantities, while geoid models uses gravimetric data with only-physical meaning the GNSS/leveling in benchmarks provides geoid height with parcial-physical or geometric-physical effect. In this context, the hybridization process of traditional gravimetric geoid takes place.

Some authors may use a different nomenclature for geoids resulting from this methodology. Generally, improvement in local contexts or "refinement" of the geoid generates no surface correction separately and simpler surfaces are used to describe the hybrid model. Featherstone et al. (1998) refer to these models as "combined geoids", since an adjustment by least squares of the data source is proposed with gravimetric GNSS leveling data. This type of combination in areas between 1,000 and 3,000 $\mathrm{km}^{2}$ have generated RMS between \pm 0.01 and $\pm 0.05 \mathrm{~m}$.

The hybridization methodology shows interesting points since hybrid models treats offsets between geoid models and GNSS/leveling in benchmarks as corrections. Therefore, this method can be seen as a way of making geoid models more consistent with GNSS positioning. The residual inconsistency present in hybrid geoid models are due to uncertainty of GNSS positioning, datum, leveling networks, gravimetry and geopotential models. 
Several countries have adopted this hybrid geoids proposal getting more consistent results with the positioning methods. The importance and the global concern is evident for the users of GNSS in converting heights with better quality. Among the countries that have adopted this methodology are: The United States - CONUS - (Roman et al. 2004, 2010, NGS 2015), Canada (NRCan 2014), Australia (Fotopoulos et al. 2002, Featherstone and Sideris 1998, Featherstone et al. 2005), South Korea (Lee et al. 2012, 2013), Japan (Kuroishi et al. 2002, Miyahara et al. 2014); China (Chen and Yang 2001, Chen and Luo 2004), Turkey (Erol et al. 2008, Erol and Erol 2013) and South Africa (Chandler and Merry 2010).

Brazil still does not have a hybrid geoid available on a regional scale for civil uses. Goldani (2006) has presented a geoid model developed only with benchmark data tracked by GNSS for the State of Paraná, the GEOIDERAAP, where RMS obtained was $\pm 0.10 \mathrm{~m}$, evidencing the model improvement over the national geoid when using this type of data in the model. The State of São Paulo has been the subject of several studies to improve the geoid through alternative methods with integration of GNSS leveling (Maia and Segatine 2003, Kavzoglu and Saka 2005, Veronez et al. 2011).

The analysis of discrepancies between undulations of benchmarks, tracked by GNSS, and the hybrid geoid model at control points indicate an interpolating noise related with its own mathematical characteristics, while the quality of the hybrid geoid model is shown by discrepancies at checkpoints considering all errors involved.

Each country can adopt a specific methodology for generation of corrections and validation. For example, the geoids in South Africa and China were evaluated by the conventional method of quality analysis. Other countries, such as Australia and the USA, do not use the conventional method of validation because the LSC methodology provides realistic estimates of the hybrid model precision.

In the case of the Japanese models, an empirical method validation is done considering the independence of other data and the values obtained confirm that the SD is compatible with the estimated model RMS. More details can be seen in Kuroishi et al. (2002) and Miyahara et al. (2014).

\section{ARTIFICIAL NEURAL NETWORK RBF}

The Artificial Neural Networks have been chosen as one of the focuses in this research study because of the facility of application, ability to learn from examples, robustness and speed of processing (Tubb 1993). This technique presents a mathematical model inspired by the neural structure of intelligent organisms, acquiring knowledge through experiences such as pattern recognition, interpolations and ratings (Wang 2003).

The RBF neural networks have a similar architecture to the MLP (multilayer perceptron) networks model. However RBF networks use distances between points for data interpolation and have only one hidden layer. The functions use distances as input, from this variable a number of neurons are activated (Wright 2003). A very interesting feature of these networks is their speed and efficiency.

The RBF networks use radial basis functions as neurons, distributed spatially. The functions use distances as input, from this variable a number of neurons are activated (Wright 2003, Haykin 2009). Some examples of radial basis functions are shown below: 


$$
\begin{aligned}
\text { Multiquadric }: \phi(r) & =\sqrt{\left(\frac{r}{\mu}\right)^{2}+1} \\
\text { InverseMult. }: \phi(r) & =\frac{1}{\sqrt{\left(\frac{r}{\mu}\right)^{2}+1}} \\
\text { Linear }: \phi(r) & =r \\
\text { Cubic }: \phi(r) & =r^{3}
\end{aligned}
$$

where $r$ is a distance; and $\mu$ is an additional smoothing parameter that needs to be estimated for each function according to the data.

The distance $\left(\phi_{(i, j)}\right)$ between point $(i)$ and the center of the radial basis function of each neuron $(j)$ during the interpolation process of the RBF networks can activate more or fewer neurons, resulting in a higher or lower contribution from neurons to the final result.

The parameters of radial basis function, the position of the center of each neuron of radial basis function, the number of neurons used and the equation of weights are defined by training the RBF Networks. During this process the RBF Networks establish a single function to the data set from the center of the radial basis function. The definition of the center of the radial basis function can be made mainly by three methods. The exact RBF kernel was used in this work. In this method, center of the radial basis function is placed on the sample data, data for forming a neuron sample. In this case, the calculation of the weights is simpler. It is necessary to solve a system of linear equations, seen that the amount of sample data and variables to be estimated is the same:

$$
\begin{gathered}
\sum_{i} \omega_{i} \phi_{(1, j)}=z_{1} \\
\sum_{i} \omega_{i} \phi_{(2, j)}=z_{2} \\
\vdots \\
\sum_{i} \omega_{i} \phi_{(n, j)}=z_{n}
\end{gathered}
$$

The result of the training process is neurons of radial basis functions with certain degrees of activation to a network of neurons. From this mesh it is possible to perform a check of the quality of the interpolation, at other sample points at which the values of the interpolated variable are known within the mesh neurons. From the differences between the generated surface and the checkpoints the average and dispersion of data reflecting the quality of the interpolator to mesh interest can be obtained. This quality, expressed in RMS shows the adjustment or the ability of the RBF network to represent real distortions.

\section{STUDY CASE FOR THE STATE OF SÃO PAULO}

A total of 338 benchmarks tracked by GNSS were made available by public organizations such as national agencies (IBGE), universities (Universidade Estadual Paulista "Júlio de Mesquita Filho"- UNESP - and the Universidade de São Paulo - USP), and private companies. All GNSS data were available in South America 
Geocentric Reference System frame (SIRGAS 2000, epoch 2000.4). The geometric height SD provided by organizations is predominantly $\pm 0.10 \mathrm{~m}$. While ortometric height SD in leveling references, adjusted according to IBGE (2011), is around \pm 0.06 and $\pm 0.08 \mathrm{~m}$. Figure 4 illustrates the standard deviations of both quantities.

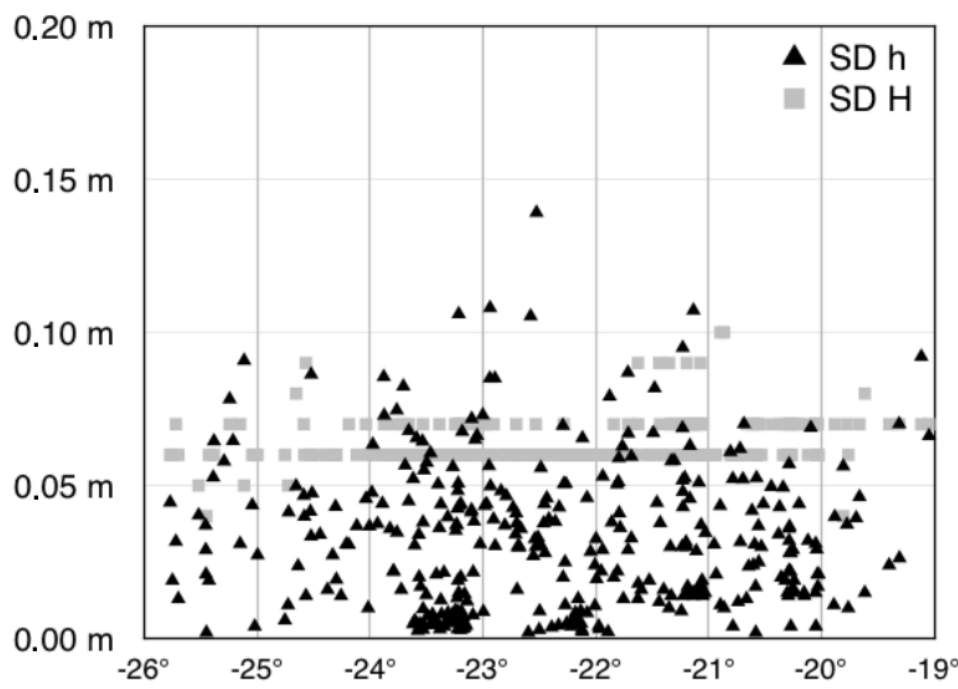

Figure 4 - Standard Deviation of ellipsoidal (h) and ortometric $(\mathrm{H})$ heights

The statistics of distortions, i.e., the discrepancy between the GNSS leveling data, considering all 338 points, and the geoid models studied (EGM2008, MAPGEO2015 e GEOIDSP2014) are presented in Table I.

TABLE I

Consistency (in meters) of gravimetric geoids EGM08, MAPGEO2015 and GEOIDSP2014 in relation to tracked leveling points in the State of São Paulo.

\begin{tabular}{rccc}
\hline & EGM08 & MAPGEO2015 & GEOIDSP2014 \\
\hline Mean: & 0.108 & 0.056 & 0.057 \\
SD: & 0.240 & 0.229 & 0.237 \\
RMS: & 0.263 & 0.236 & 0.244 \\
Max.: & 1.677 & 1.388 & 1.386 \\
& & 0.021 & -0.009 \\
Skewness: & 0.242 & 12.148 & 11.503 \\
\hline Kurtosis: & 13.504 & & \\
\hline
\end{tabular}

SD of data between the models is similar, though the accuracy factor (RMS) of EGM2008 is impaired due to a higher trend of the mean in model. MAPGEO2010 and GEOIDSP2014 have a similar consistency through the use of the same method to obtain the geoid model and the long and medium wavelength, also be provided by a geopotential model of the same series, EIGEN. The skewness and kurtosis coefficients indicate proximity that distortions have in relation to a normal distribution. A skewness coefficient close by 
zero (null) values indicates a symmetric distribution of distortions. In the case of EGM2008 distortions, this coefficient showed less symmetrical distribution with respect to other models. Discrepancies obtained with EGM2008, MAPGEO2015 and GEOIDESP2014 models showed similar platykurtic behavior.

Data distortions are shown in Figure 5 (a) in histograms (left) and punctuality (right). The presence of high discrepancies, some of them bigger than 1 meter, is noticed in data. Since these points can indicate an existence of errors in orthometric and/or geometric heights, it is proposed a filtering for elimination of gross errors or outliers data in order to obtain a hybrid geoid model of the best possible quality. We assume that distortions between geoid models and GNSS data should present a normal distribution when filtering data.
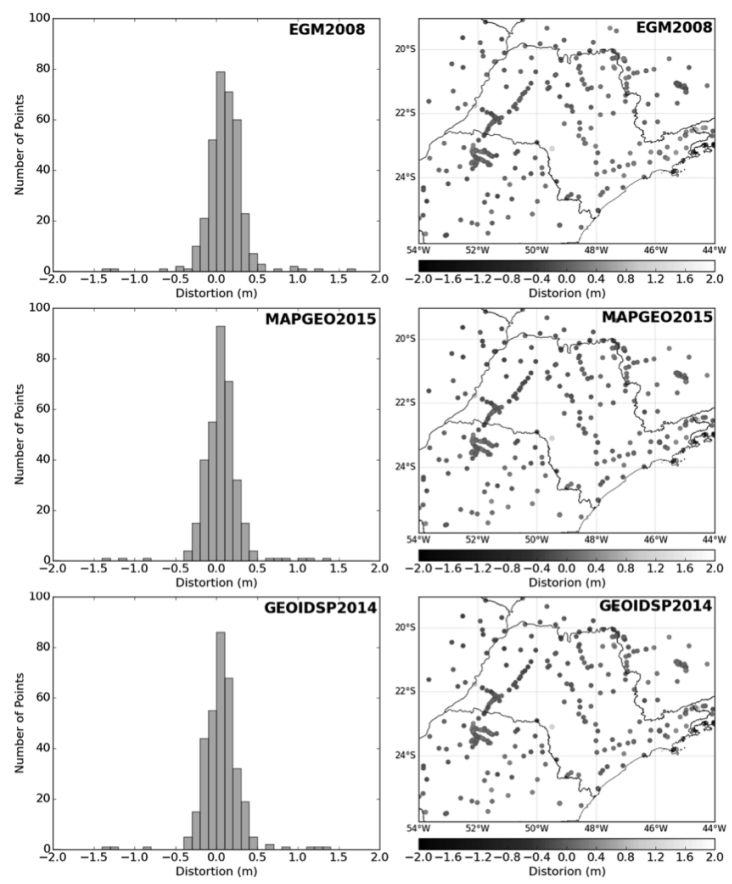

(a)
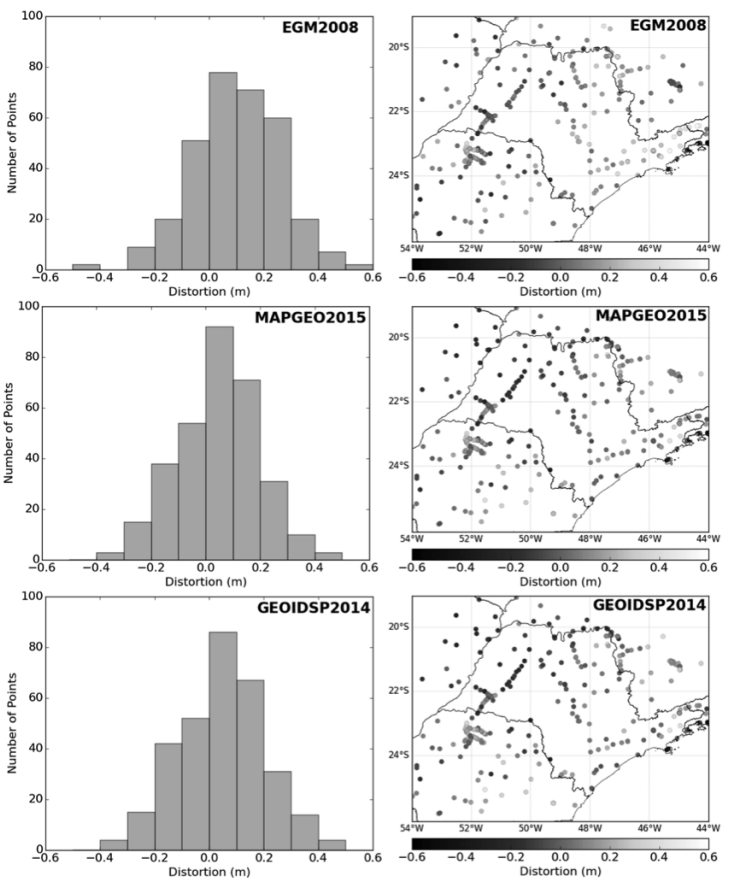

(b)

Figure 5 - Distortions (in meters) of geoid models EGM2008, MAPGEO2015 and GEOIDSP2014 regarding benchmarks tracked by GNSS (a) before and (b) after filtering data (see the colors in the online version).

Considering the amount of sample points, using the interval $[\mu \pm 3 \sigma]$ statistically provides a discard of $0.27 \%$ of data without non-normal error, equivalent to approximately one point. From this idea, the filtering distortion data was carried out by adopting this range in each model. Also, two steps are proposed for the filtering. First the selection of data in relation to the total sample of data, the second step is to disregard points that have inconsistent distortion with a group of neighboring points, i.e. geometrically adjacent.

In the initial step, intervals are calculated based on the full set of data statistics (Table I), i.e., 338 points tracked by GNSS. The feature of this filter is the elimination of spaced distortions from the averaged data. As a result, the statistical distortions are considerably reduced. Respectively for EGM08, MAPGEO2010 and GEOIDSP2014 the RMS reduced $0.068 \mathrm{~m}, 0.065 \mathrm{~m}$ and $0.066 \mathrm{~m}$; while the maximum distortion values decreased $0.972 \mathrm{~m}, 0.683 \mathrm{~m}$ and $0.700 \mathrm{~m}$. Table II shows the statistics of distortions, after filtering the data.

The second filtering step also used averages and standard deviations, but, checking locally if each distortion is within the region range $[\mu \pm 3 \sigma]$. However, the selection of the next points requires the definition 
TABLE II

Consistency (in meters) of gravimetric geoids EGM08, MAPGEO2015 and GEOIDSP2014 in relation to tracked leveling points after the first step of filtering data.

\begin{tabular}{rccc}
\hline & EGM08 & MAPGEO2015 & GEOIDSP2014 \\
Mean: & 0.103 & 0.054 & 0.054 \\
SD: & 0.165 & 0.162 & 0.169 \\
RMS: & 0.195 & 0.171 & 0.178 \\
Max.: & 0.705 & 0.705 & 0.686 \\
& & & \\
Skewness: & -0.015 & 0.249 & 0.224 \\
& & 0.633 & 0.399 \\
Kurtosis: & 0.727 & 0.395 \\
\hline
\end{tabular}

of some parameters: the number of minimum or maximum points that must be taken into account and/or the minimum or maximum distance to search for neighboring points.

An analysis shows that, considering $2^{\circ}$ distance as the search radius, $94 \%$ of data has at least 30 neighbor points, corresponding to approximately $10 \%$ of the total amount of data from the study area. However, borders are more isolated in the study area, with greater difficulty in finding neighboring points. Consequently these points need to overreach the search radius to meet a certain minimum number of points. The solution found was to reduce the number of points for the calculation of statistics. It was observed that the use of 10 neighboring points for a search does not exceed a maximum radius of $2^{\circ}$ and $86 \%$ of the data points was still found at a distance of at most $1^{\circ}$. Therefore the additional parameter for step 2 was to consider the first 10 closer neighbors to check whether each distortion is within the region range $[\mu \pm 3 \sigma]$.

After the second filtering step, new statistical distortions were calculated (Table III). Again the statistics showed reductions. Respectively for EGM08, MAPGEO2010 and GEOIDSP2014, the RMS reduced 0.008 $\mathrm{m}, 0.015 \mathrm{~m}$ and $0.015 \mathrm{~m}$; and the maximum values distortions decreased $0.168 \mathrm{~m}, 0.262 \mathrm{~m}$ and $0.232 \mathrm{~m}$. In addition, comparing statistics before and after the filtering process, we noted higher attenuations. For EGM08, MAPGEO2010 and GEOIDSP2014, respectively, the RMS decreased $0.076 \mathrm{~m}, 0.080 \mathrm{~m}$ and 0.081 $\mathrm{m}$; while the maximum values reduced $1.140 \mathrm{~m}, 0.945 \mathrm{~m}$ and $0.932 \mathrm{~m}$.

The data distortions, after second filtering step, are shown in Figure 5 (b) in histograms (left) and punctuality (right).

A summary of the amount of remaining points after each filtering stage is shown in Table IV.

\section{HYDEGM, HYDMAPGEO AND HYDGEOIDSP}

After filtering data of benchmarks tracked by GNSS, three hybrid geoids were obtained from three different gravimetric geoid models where linear RBF was used for corrector surface generation. The first was generated from EGM2008 with degree and order 2160 (HYDEGM), the second model was modeled using MAPGEO2015 (HYDMAPGEO) and the third model using GEOIDSP2014 (HYDGEOIDSP). 
TABLE III

Consistency (in meters) of gravimetric geoids EGM08, MAPGEO2015 and GEOIDSP2014 in relation to leveling points tracked by GNSS after the second step of filtering data.

\begin{tabular}{rccc}
\hline & EGM08 & MAPGEO2015 & GEOIDSP2014 \\
Mean: & 0.102 & 0.047 & 0.047 \\
SD: & 0.157 & 0.149 & 0.156 \\
RMS: & 0.187 & 0.156 & 0.163 \\
Max.: & 0.537 & 0.443 & 0.454 \\
& & -0.088 & -0.058 \\
Skewness: & -0.134 & -0.144 & -0.202 \\
\hline Kurtosis: & 0.537 & & \\
\hline
\end{tabular}

TABLE IV

Number of remaining points after each filtering step for EGM08 model MAPGEO2015 and GEOIDSP2014.

\begin{tabular}{cccc}
\hline & EGM08 & MAPGEO2015 & GEOIDSP2014 \\
\hline Initially & 338 & 338 & 338 \\
Step 1 & 330 & 331 & 331 \\
Step 2 & 319 & 317 & 315 \\
\hline
\end{tabular}

Discrepancies between the undulations of hybrid models and benchmarks tracked by GNSS, which did not participate in the model generation (10\%), were used for validation. For comparative purposes, the statistics of validation points for gravimetric geoids are shown in Table V.

TABLE V

Consistency (in meters) of gravimetric geoids EGM08, MAPGEO2015 and GEOIDSP2014 regarding checkpoints.

\begin{tabular}{cccc}
\hline & EGM08 & MAPGEO2015 & GEOIDSP2014 \\
\hline Mean: & 0.103 & 0.048 & 0.048 \\
SD: & 0.161 & 0.146 & 0.160 \\
RMS: & 0.191 & 0.153 & 0.167 \\
Max.: & 0.546 & 0.443 & 0.454 \\
\hline
\end{tabular}


Surface correction of gravimetric geoids EGM2008, MAPGEO2015 and GEOIDSP2014 (top-down) are shown on the left side of Figure 6, where dots represent data used during the training phase of linear $\mathrm{RBF}$, and triangles are points used for validation statistics of hybrid geoid models. On the right side in the same figure discrepancies of validation points with benchmarks tracked by GNSS are shown.
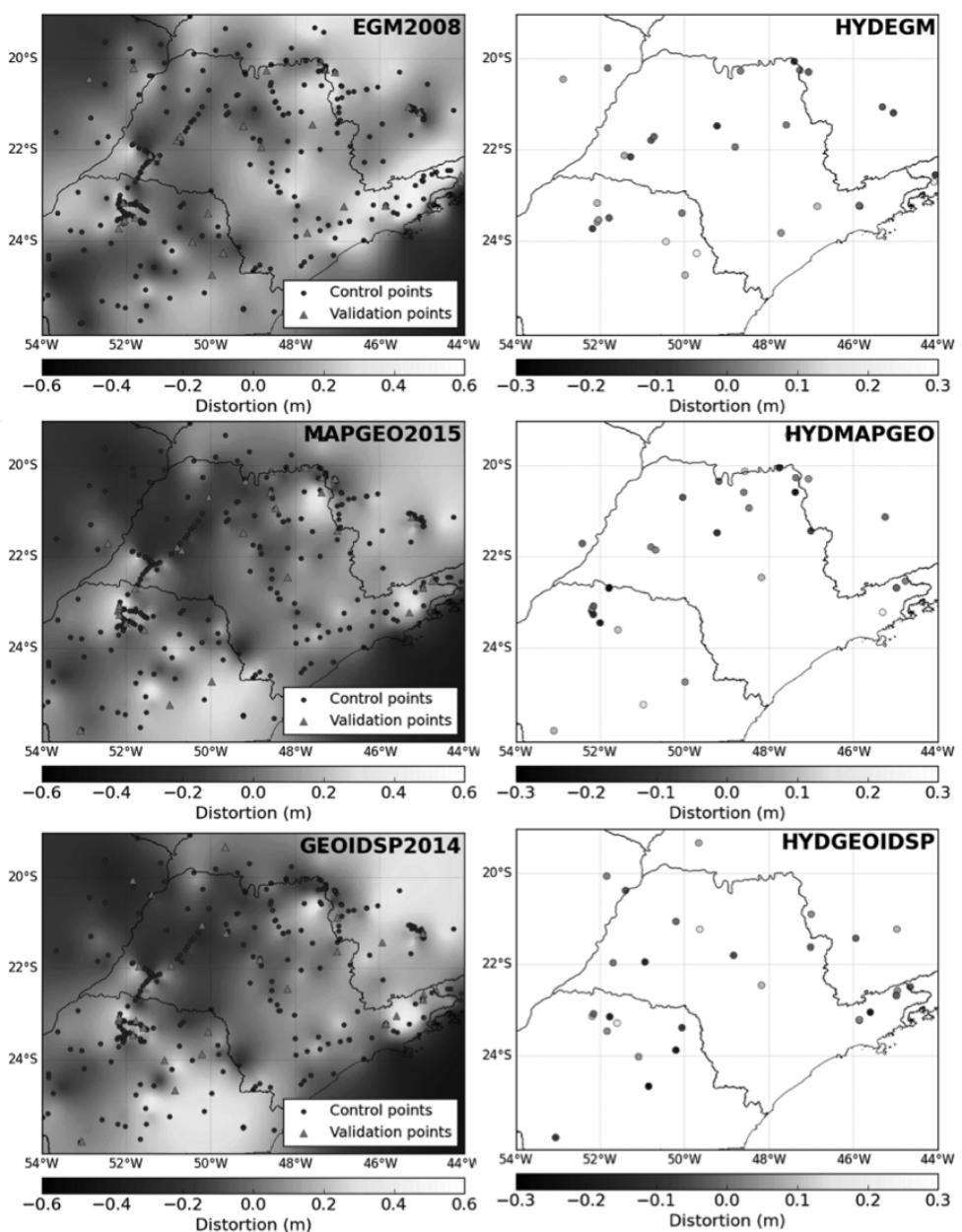

Figure 6 - Geoid corrector surfaces (left) generated using 90\% points randomly selected (dots), and $10 \%$ points for checking (triangles), and punctual discrepancy of validation points and benchmarks tracked by GNSS (right) (see the colors in the online version).

The statistics obtained for the geoid hybrid models, evaluated with the same points used in the validation of their respective gravimetric geoids is shown in Table VI.

Comparing the statistics of gravimetric and hybrid models, it is possible to notice reduction trends: HYDEGM showed a reduction of $0.104 \mathrm{~m}$; HYDMAPGEO decreased $0.035 \mathrm{~m}$; and HYDGEOIDSP indicated an attenuation of $0.047 \mathrm{~m}$. Regarding standard deviations, hybrid models showed reductions of 0.054 , 0.043 and $0.062 \mathrm{~m}$, respectively. Consequently, with the application of the proposed methodology, the RMS of hybrid models decreased between 30 and $40 \%$ compared to the gravimetric models, indicating model improvements. Another factor that deserves mention is the reduction of the maximum offset values.

In order to evaluate the use of RBF neural networks for modeling of distortions another interpolation method was used while maintaining the same methodology of choice points for generation of surface dis- 
TABLE VI

Consistency (in meters) of hybrid geoids HYDEGM, HYDMAPGEO and HYDGEOIDSP generated by linear RBF networks regarding validation points.

\begin{tabular}{cccc}
\hline & HYDEGM & HYDMAPGEO & HYDGEOIDSP \\
\hline Mean: & -0.001 & 0.013 & 0.001 \\
SD: & 0.107 & 0.103 & 0.098 \\
RMS: & 0.107 & 0.104 & 0.098 \\
Max.: & 0.276 & 0.314 & 0.272 \\
\hline
\end{tabular}

tortions. Kriging was chosen as the interpolation method since this method presents equivalent results to the RBF networks, according to Fazio and Roisenberg (2013). The statistics for validation points concerning hybrid geoids generated by the Kriging interpolation method with linear variogram is shown in Table VII.

TABLE VII

Consistency (in meters) of hybrid geoids KHYDEGM, KHYDMAPGEO and KHYDGEOIDSP generated by Kriging (linear variogram) regarding validation points.

\begin{tabular}{cccc}
\hline & KHYDEGM & KHYDMAPGEO & KHYDGEOIDSP \\
\hline Mean: & 0.006 & 0.022 & 0.003 \\
SD: & 0.131 & 0.136 & 0.116 \\
RMS: & 0.131 & 0.138 & 0.116 \\
Max.: & 0.379 & 0.338 & 0.352 \\
\hline
\end{tabular}

The differences between means of hybrid models HYDEGM, HYDMAPGEO and HYDGEOIDSP by linear RBF and Kriging reached $0.008 \mathrm{~m}$; while RMS has differences of $0.024,0.034$ and $0.018 \mathrm{~m}$; and the maximum value differences were between 0.024 and $0.104 \mathrm{~m}$. The hybrid models by linear RBF therefore showed an RMS of 15 to $25 \%$ lower compared to hybrid models by Kriging. This comparison shows that the linear RBF neural networks were more suitable in the study case.

\section{CONCLUSIONS}

When GNSS positioning is used for leveling purposes, users need to take account of height transformation. So, an accurate geoid model becomes an essential topic and methods and techniques on the geoid calculation are being improved. Since the consistency can also represent data quality, some authors focus on correcting the inconsistency of the geoid model. This method was emphasized in this paper. 
Given the current need for a geoid undulation model of better quality for converting GNSS positioning geometric heights in orthometric heights, three geoid models were developed from the EGM08, MAPGEO2015 and GEOIDSP2014 using the hybridization method in the State of São Paulo, respectively: the HYDEGM the HYDMAPGEO and HYDGEOIDSP. In these models the use of benchmarks tracked by GNSS data is essential in the process of hybridization. 338 level references, these adjusted by the IBGE (2011), were used in the study area. However, after carrying out data filtering remained 319, 317 and 315 points for generating the hybrid models, respectively to HYDEGM, HYDMAPGEO and HYDGEOIDSP.

Since a specific interpolation can better represent the spatial reality of the data and the study site, it was found essential the selection of the interpolation method to represent the corrector surface, which must be performed empirically. In this study two interpolators were tested: RBF neural network and Kriging. The RBF interpolation showed 15 to 25\% lower RMS by comparison with Kriging. HYDEGM, HYDMAPGEO and HYDGEOIDSP showed, respectively, an RMS of $0.107 \mathrm{~m}, 0.104$ and $0.098 \mathrm{~m}$.

Results of the standard deviations of the distortions between hybrids geoids and leveling data tracked by GNSS reflect consistency between the GNSS positioning and leveling reference points used to validate the models. In conclusion, the errors of the methods of positioning and leveling limit the accuracy of hybrid geoids.

\section{ACKNOWLEDGMENTS}

The authors acknowledge Coordenação de Aperfeiçoamento de Pessoal de Nível Superior (CAPES) for supporting this research. We are grateful to Instituto Brasileiro de Geografia e Estatística (IBGE), Laboratório de Topografia e Geodésia (LTG) from USP and Department of Cartography from UNESP for providing the GNSS data. We would also like to thank the reviewers and the editor for their comments and suggestions on this manuscript.

\section{REFERENCES}

BARTHELMES F AND KÖHLER W. 2012. International Centre for Global Earth Models (ICGEM). The Geodesists Handbook 86(10): 932-934.

BLITZKOW D, MATOS ACOC, CAMPOS IO, ELLMANN A, VANÍČEK P AND SANTOS MC. 2009. An attempt for an Amazon geoid model using Helmert gravity anomaly. In: Observing our Changing Earth, Springer, p. 187-194.

CHANDLER G AND MERRY CL. 2010. The South African geoid 2010: SAGEOID10. PositionIT, p. 29-33.

CHEN YQ AND LUO Z. 2004. A hybrid method to determine a local geoid model - Case study. Earth Planets Space 56(4): $419-427$. CHEN YQ AND YANG ZJ. 2001. A hybrid method to determine the Hong Kong geoid. In: FIG Working Week. South Korea.

ELLMANN A AND VANÍČEK P. 2007. UNB application of Stokes-Helmert's approach to geoid computation. J Geodyn 43(2): 200-213.

EROL B AND EROL S. 2013. Learning-based computing techniques in geoid modeling for precise height transformation. Comput Geosci 52: 95-107.

EROL B, EROL S AND ÇELIK RN. 2008. Height Transformation using Regional Geoids and GPS/levelling in Turkey. Surv Rev 40: 2-18.

FAZIO VS AND ROISENBERG M. 2013. Spatial Interpolation: An Analytical Comparison Between Kriging and RBF Networks. In: Proceedings of the 28th Annual ACM Symposium on Applied Computing, SAC '13, p. 2-7. New York, NY, USA: ACM.

FEATHERSTONE WE. 2000. Refinement of gravimetric geoid using GPS and leveling data. J Surv Eng 126(2): $27-56$.

FEATHERSTONE WE, DENTITH MC AND KIRBY JF. 1998. Strategies for the accurate determination of orthometric heights from GPS. Surv Rev 34(267): 278-296. 
FEATHERSTONE WE AND SIDERIS MG. 1998. Geodesy on the Move: Gravity, Geoid, Geodynamics and Antarctica, chapter Modified Kernels in Spectral Geoid Determination: First Results from Western Australia, p. 188-193. Springer Berlin Heidelberg.

FEATHERSTONE WE, SPROULE DM, GOOS JM, KIRBY JF, KUHN M AND CLAESSENS SJ. 2005. Towards the new AusGeoid model. In: Proceedings of SSC. Melbourne: Spatial Sciences Institute.

FÖRSTE C, BRUINSMA SL, ABRIKOSOV O, LEMOINE JM, MARTY JC, FLECHTNER F, BALMINO G, BARTHELMES F AND BIANCALE R. 2014. EIGEN-6C4-The latest combined global gravity field model including GOCE data up to degree and order 1949 of GFZ Potsdam and GRGS Toulouse. In: EGU General Assembly Conference Abstracts, volume 16 of EGU General Assembly Conference Abstracts, p. 3707. GFZ Data Services.

FÖRSTE C ET AL. 2013. EIGEN-6C3stat - the newest High Resolution Global Combined Gravity Field Model based on the 4th Release of the GOCE Direct Approach.

FOTOPOULOS G, FEATHERSTONE WE AND SIDERIS MG. 2002. Fitting a gravimetric geoid model to the Australian Height Datum via GPS data. Gravity and Geoid, p. 173-178.

FREITAS SRC AND BLITZKOW D. 1999. Altitudes e Geopotencial. In: IGeS Bulletin N.9 - International Geoid Service, Milan, p. $47-62$.

FUKUDA Y, KURODA J, TAKABATAKE Y, ITOH J AND MURAKAMI M. 1997. Improvement of JGEOID 93 by the Geoidal Heights Derived from GPS/Leveling Survey. In: Gravity, Geoid and Marine Geodesy. Springer Berlin Heidelberg 117: $589-596$.

GOLDANI D. 2006. Modelo geoidal de alta resolução para o Estado do Paraná: aplicação da Transformada Rápida de Fourier Stokes e do valor do potencial do geoide na definição da superfície de referencia vertical. Master's thesis, Universidade Federal do Paraná Curitiba (UFPR), Curitiba-PR, Brazil. (Unpublished).

GUIMARÃES GN, DE MATOS ACOC AND BLITZKOW D. 2015. New Geoid Model in the State of São Paulo. International Association of Geodesy Symposia, p. 1-7.

HARDY RL. 1975. Research results in the application of multiquadratic equations to surveying and mapping problems. Surv Mapp 35(12): 321-332.

HAYKIN SS. 2009. Neural networks and learning machines. Prentice Hall, $3^{\text {rd }}$ edition.

IBGE. 2011. Ajustamento Simultâneo da Rede Altimétrica de Alta Precisão do Sistema Geodésico Brasileiro: Relatório. Technical report, Instituto Brasileiro de Geografia e Estatística, Rio de Janeiro, Brazil.

IBGE. 2015. O novo modelo de ondulação geoidal do Brasil: MAPGEO2015. Technical report, Instituto Brasileiro de Geografia e Estatística, Rio de Janeiro, Brazil.

ICGEM - INTERNATIONAL CENTRE FOR GLOBAL EARTH MODELS. 2015. Root mean square (RMS) about mean of GPS/levelling minus gravity field model derived geoid heights [m]: Evaluation of the models.

JEKELI C. 2000. Heights, the geopotential, and vertical datums. Technical Report 459, Ohio State University, Department of Civil and Environmental Engineering and Geodetic Science.

KAVZOGLU T AND SAKA MH. 2005. Modelling local GPS/levelling geoid undulations using artificial neural networks. J Geodesy 78(9): 520-527.

KOTSAKIS C AND SIDERIS MG. 2001. On the Adjustment of Combined GPS/Levelling/Geoid Networks. In: Benciolini B (Ed), IV Hotine-Marussi Symposium on Mathematical Geodesy, volume 122 of International Association of Geodesy Symposia, Springer Berlin Heidelberg, p. 165-165.

KUROISHI Y. 2009. Improved geoid model determination for Japan from GRACE and a regional gravity field model. Earth Planets Space 61(7): 807-813.

KUROISHI Y, ANDO H AND FUKUDA Y. 2002. A new hybrid geoid model for Japan, GSIGEO2000. J Geodesy 76(8): $428-436$.

LEE DH, YUN HS, JUNG HI, CHO JM, CHO JH, JUNG WC AND HWANG JS. 2013. Transformation of Vertical Datum Surface in the Coastal Area using Hybrid Geoid Models. J Coastal Res 2(65): 1427-1432.

LEE DH, YUN HS, SUH YC, HWANG JS AND MIN BI. 2012. KGEOID10: A New Hybrid Geoid Model in Korea. In: Abbasi A and Giesen N (Eds), EGU General Assembly Conference Abstracts, volume 14 of EGU General Assembly Conference Abstracts, p. 7383.

MAIA TCB AND SEGATINE PCL. 2003. Geoidal model Obtained by Multilayer Perceptron Neural Network. In: WEEK 2, Saporo - Japan: IUGG2003 2: 171.

MARTINEC Z. 1998. Boundary-value problems for gravimetric determination of a precise geoid. Lecture Notes in Earth Sciences 7.

MARTINEC Z AND VANÍČEK P. 1994. Direct topographical effect of Helmert's condensation for a spherical approximation of the geoid. Manuscr Geodaet 1(19): 257-268. 
MATOS ACOC, BLITZKOW D, GUIMARÃES GN, LOBIANCO MCB AND COSTA SMA. 2012. Validação do MAPGEO2010 e comparação com modelos do geopotencial recentes. Bol Cienc Geod 18: 101-122.

MIYAHARA B, KODAMA T AND KUROIHSI Y. 2014. Development of new hybrid geoid model for Japan,“GSIGEO2011”. Bulletin of the Geospatial Information Authority of Japan 62: 12.

NGS - NATIONAL GEODETIC SURVEY. 2015. The NGS Geoid Page.

NRCAN - NATURAL RESOURCES CANADA. 2014. Tools and Applications.

PAVLIS NK, HOLMES SA, KENYON SC AND FACTOR JK. 2008. An Earth gravitational model to degree 2160: EGM2008. In: Solid Earth, p. 1978-2012. Vienna, Austria: General Assembly of the European Geosciences Union.

PAVLIS NK, HOLMES SA, KENYON SC AND FACTOR JK. 2012. The development and evaluation of the Earth Gravitational Model 2008 (EGM2008). J Geophys Res: Solid Earth (1978-2012) 117(B4).

PLAG HP AND PEARLMAN M. 2009. Global geodetic observing system: meeting the requirements of a global society on a changing planet in 2020. Springer Dordreht Heidelberg.

ROMAN DR, WANG YM, HENNING W AND HAMILTON J. 2004. Assessment of the new national geoid height model, GEOID03. SaLIS 64(3): 153-162.

ROMAN DR, WANG YM, SALEH J AND LI X. 2010. National geoid height models for the United States: USGG2009 and GEOID09. In: Proceedings of the ACSM-MARLS-UCLS-WFPS conference, p. 20-23. Salt Lake City, UT, USA.

SEEBER G. 2003. Satellite Geodesy: foundations, methods, and applications. Walter de Gruyter.

SIDERIS MG. 2013. Geoid determination by FFT techniques. In: Geoid Determination, p. 453-516. Springer Berlin Heidelberg.

SJÖBERG LE. 2006. A refined conversion from normal height to orthometric height. Stud Geophys Geod 50(4): 595-606.

TORGE W. 2001. Geodesy. Walter de Gruyter.

TUBB NR. 1993. A development path to success in neural computing. Expert Systems Applications 9(5): 5-9.

VERONEZ MR, FLORÊNCIO DE SOUZA S, MATSUOKA MT, REINHARDT A AND MACEDÔNIO DA SILVA R. 2011. Regional mapping of the Geoid using GNSS (GPS) measurements and an artificial neural network. Remote Sens 3(4): 668-683. WANG SC. 2003. Artificial neural network. In: Interdisciplinary Computing in Java Programming, p. 81-100. Springer US.

WRIGHT GB. 2003. Radial basis function interpolation: numerical and analytical developments. Ph.D. thesis, University of Colorado at Boulder, Department of Applied Mathematics, Boulder, CO, United States of America. 